\title{
The 2nd Generation Street Children (SGSC) in Accra: Developing Teaching Strategies To Enhance Positive Learning Outcomes in Schools
}

\author{
Alhassan Abdul-Razak Kuyini \\ Sultan Hassanal Bolkia Institute of Education \\ Psychological Studies \& Human Development, University of Brunei \\ malti26@hotmail.com
}

Okechuwu Abosi (Corresponding author)

Sultan Hassanal Bolkia Institute of Education

Psychological Studies \& Human Development, University of Brunei, Jalan Tungku link BE 1410,

Brunei Darussalam

Tel: 673-246-3001 ext. 1572.

Email: okechukwuabosi@yahoo.com \& okechukwu.abosi@ubd.edu.bn

Received: June 21, 2011

doi:10.5430/wje.v1n2p161
Accepted: July 17, $2011 \quad$ Published: October 1, 2011

URL: http://dx.doi.org/10.5430/wje.v1n2p161

\begin{abstract}
Ghana is witnessing an increasing number of 2nd generation street children (SGSC) living in the street of Accra, the capital city as a result of many factors including teenage pregnancy among street girls, ethnic conflicts and rural-urban migration. Street presents enormous risks to street children; they are excluded from safe-family environment, basic services like health and education, and protection against exploitation. This article explored the inclusion of 27 SGSC in regular schools in Accra. Using qualitative methods, we obtained data from 15 teachers and social workers directly involved in the inclusion project. Finding revealed that SGSC were provided with pedagogical materials, daily feeding and school-related needs to encourage school attendance. To enhance positive learning outcomes of SGSC, teachers employed explicit instruction, cooperative learning, and social skills instruction. The study concludes that inclusion of SGSC in regular schools requires a willing and responsible school leadership; a comprehensive needs assessment including street mapping and social investigation on SGSC; financial support; and training of school personnel on streetism.
\end{abstract}

Keywords: Second generation street children, Inclusive education, Positive learning outcomes

\section{Introduction}

For the past three decays, trend in educational policy in many countries has been focusing on promoting inclusive education (IE) while fighting vigorously to end exclusion (Peter, 2003; UNESCO, 2009). This development is reflected in Ghana education policy (Ghana Education Strategic Plan 2003-2015). Ghana government has adopted the principles of IE enshrined in the international declarations of the Universal Human Rights, 1948, Education for All (EFA), 1990, Salamanca Declaration, 1994 and Dakar Framework for Action, 2000. In Ghana, these declarations serve as blueprint and framework on Special Needs Education (Casely-Hayford, 2002; Kuyini, 2007; Obi, Mamah \& Avoke, 2007). At both international and national levels, the aforementioned declarations provide a unique opportunity to place street children's education within the wider framework of EFA (GESP 2003-2015; UNESCO2009).

However, IE in Ghana has focused, primarily, on children with visible disabilities - children with intellectual disability, hearing impairment while forgetting of the underserved school children and school drop-outs (Abosi, 2007; Anthony, 2009; Casely-Hayford, 2002; Obi, Mamah \& Avoke, 2007; Ghana National Coalition for Right of Children (GNCRC), 2005;) who end up spending their childhood in the streets and label as street children (Catholic Action for Street Children(CAS), 2003, 2006; 2010; Peter, 2003). This form of exclusion exists simply because the notion of inclusion is often associated only with children with disabilities. 
The phenomenon of streetism is a global problem which is not limited to only the developing world (Brink, 2001; Hemenway, 1996; Ennew, 2003). Most of the industrialized countries have their own orphans, runaways, abused and neglected children (Hemenway, 1996; UNESCO, 2009). In 2005, UNESCO and P.A.U. Education estimated more than 130 million children worldwide living on the street and recommended education, which is a fundamental human right of every child, as one of the essential means of getting children out of streets (P.A.U. Education \& UNESCO, 2005).

In Ghana, it is estimated that 21,140 street children, 7500 street mothers (below 20years) and 14,500 urban poor children live in the street of Accra alone (CAS, 2006; 2010). The Ghana Government, since 1997, has put several important measures in place to curb, if not eliminate, this problem and to bring Ghana into conformity with the international human rights standards on children. These measures include: The Child Rights Legislative Reforms (the Criminal Code (Amendment) Act 1998, (Act 554), The Children's Act 1998, (Act 560), and Child Rights Regulations 2002 (LI1705). In addition, there are polices on Free Compulsory Universal Basic Education (FCUBE) and School Feeding Programme (GNCRC, 2005). In spite of the legislative and policy achievements, the implementation of these policies has not ensured the protection of Ghanaian children's basic rights and welfare. As a result, children whose basic needs and rights are not met or protected at home find their way to the street.

\subsection{Background}

CAS (2003) categorized Ghanaian "street children" into three:

a.) There children in the street of Accra who have parents and a "home" to go to. These children are supported. They belong to the category of urban poor children

b.) There are children who live and work in the streets and have nobody to support them(street children)

c.) And there are children who were born in the street of Accra. Their mothers are street mother $\left(2^{\mathrm{ND}}\right.$ generation of street children) (p.7).

This study deals with the third category- $2^{\text {nd }}$ Generation Street Children (SGSC). The definition of SGSC, in this study, is widened to incorporate children brought to the street at the age less than three. Therefore, the SGSC are children born on the street or brought to the street at the age less than three by mothers or fathers who live in the street or slum and receive no support from anybody.

Reasons that compelled Ghanaian children to decide to live on the street are not so different from that of other developing countries. Evidence from literature indicate that Ghanaian street children leave their families and familiar environments to streets to: search for greener pastures, safety, because of poverty, domestic violence, neglect, single parenthood, motivation from friends, truancy, social change, high population, a combination of weak performance in school and drop-out, education and rural underdevelopment (Brink, 2001, CAS, 2003; 2006; 2009 deBeritez, 2001; Ennew, 2003; Hemenway, 1996 SAP, 2011; Street Action, 2010).

No matter how street children are defined and the experiences they might have acquired on the streets, one thing about them that is of great value to educators is - how to win them back to school, retain them and motivate them to learn with peers or equip them with vocational skills to enable them leave the streets completely (Brink, 2001; CAS, 2003; 2006; 2010; GNCRC, 2005; P.A.U. Education \& UNESCO, 2005; UNESCO, 2009).

As part of efforts made to deal with streetism in Ghana, Ricerca e Cooperazione, Italian Development Agency in collaboration with the Department of Social Welfare of Ghana and two leading local NGOs- CAS and SAID initiated a 3-year enhancement project (2007/8-2010/11) aimed at reintegrating street children and their mothers into the conventional Ghanaian society. As a result, street mothers were trained in vocation, while their children were enrolled in schools to acquire basic education.

\subsection{The purpose of the study}

The purpose of this study was to evaluate the inclusion of SGSC in regular schools, concentrating on the process of inclusion, strategies for retention, learning outcome and challenges encountered during their inclusion.

\subsection{Research questions}

The research answered the following questions:

a.) What was the process involved in the inclusion of SGSC in regular schools?

b.) What strategies were used to improve:

retention and class attendance,

learning outcomes of SGSC in schools? 
c.) What challenges were encountered during the inclusion of SGSC in schools?

\section{Conceptual framework}

This article adapts special education model developed by Holmberg \& Lyster (Ekeberg \& Holmberg, 2002) and World Health Organization (WHO) model for working with street children (WHO/MSD/MDP/100.14) to discuss the inclusion of SGSC in regular schools in Accra. The framework argues that any successful inclusion of street children in regular school should be engaged in five key series of actions with street children. The five key actions include: situation assessment of SGSC's situation, strategic planning, implementation, continuous monitoring and assessment, and reporting of success and challenges.

The inclusion of SGSC in regular schools starts with the situation assessment to identify problems and needs. The assessment team should consist of special educators, regular teachers and social workers (with extensive experience on streetism). The aim of this assessment is to get insight into and understanding of street children's life, their developmental level and strategies suitable for their condition. Basically, the team identifies the main problems, needs and decides, with street children, what is to be addressed. The methods of assessment may include enlightened conversation with street children, parents, if any, gang leaders, and street children-network. The need for critical assessment of children's conditions before setting any intervention is also supported by (Ekeberg \& Holmberg, 2002; Mastropieri \& Scruggs, 2000; Salend, 2001; UNESCO, 2009).

The next stage of this model involves strategic planning, setting realistic and achievable objectives by outlining strategies, activities, and resources (human and financial) needed to carry out the set objectives. Again, here roles and responsibilities at individual and system level should be clarified. Decision about practical issues including grade levels, uniforms and pedagogical materials should be agreed upon and provided before street children start school. Provision of the needed items to street children will boost their self-esteem and avoids negative feelings such as shyness and the tendency of being labeled as dirty kids (CAS, 2003; 2006).

The third phase of the model is the implementation. Our model for inclusion of street children argues that success and failure of street children's inclusion in regular schools lies in the implementation processes. This is where teachers and other professionals comprising social workers and special educators come in to conduct all the activities proposed at the planning stage. While implementing the proposed activities, the implementing team is to be monitoring, assessing and evaluating the impact of the strategies on the included street children and the peers continuously. The inclusion team has to meet regularly to discuss and revise strategies to improve inclusion. The reporting component is meant to disseminate findings for stakeholders through regular conference meetings and publications. All the five phases of the framework are interrelated and inclusion should be based on individual SGSC's characteristics and background (UNESCO, 2009). Schools must offer all possibilities and opportunities with range of working methods to ensure that no SGSC are excluded from social and academic participation in schools (UNESCO, 2009).

\section{Methodology}

\subsection{Participants}

Participants consisted of 9 regular school teachers, 3 special educators and 3 social workers. The 9 teachers were drawn from seven regular schools where SGSC were enrolled. The criteria for selection of teachers was based on the ages (9-12years) of their included SGSC, and must be born on street or brought to the street at an age not more that 3 years. All regular teachers had 4-15 years teaching experiences with in-service training in special education. The special educators had 2-4 years experiences as special educators and more than 5 years experiences in teaching primary schools. Similarly, social workers had 6-9 years experiences working with street children. The total number of SGSC was 27 SGSC aged between 9 and 12 years and made up of 18 girls and 9 boys. With the exception of 8 SGSC who were brought to the street at the age between 2-3years, all the 19 SGSC were born on the street. More than half (62\%) of SGSCS had 1-2 year kindergarten and school experiences. All participants agreed willingly to participate in the study. All names of participants including the schools were made anonymous to prevent identification of the participants.

\subsection{Data collection methods}

Three types of methods were used in the study and lasted for two years (October, 2008- November, 2010).

\subsubsection{Semi- structured interviews}

Teachers were interviewed on the general progress of the SGSC in school using the following guidelines:

a.) SGSC general wellbeing in school

b.) Participation during lessons and extra curricula activities 
c.) SGSC response to teaching strategies used for inclusion

d.) problems and challenges encountered

In addition, social workers were interviewed on school-home (street) situation, specifically, on SGSC's social and psychological wellbeing, motivation and strategies for school attendance and retention.

\subsubsection{Documentary analysis}

SGSC's school terminal and monitoring reports were examined. The analysis of school reports was centered on SGSC's school attendance and retention while analysis of reports on situation assessment and termly monitoring reports (jointly written by teachers and social workers) provided background information and SGSC's responses to inclusion strategies.

\subsubsection{Ethnographic fieldnotes}

The ethnographic field method involves the collection of detailed fieldnotes written during field visits to schools and the living places of SGSC (Hammersley et at. 2003; Kvale, 1996). The field visits were conducted twice in every school term to observe and interact with teachers, social workers and SGSC to generate data on the general ecology of the living situation of SGSC, the nature of teaching and learning activities, and supports provided to SGSC in classrooms. Fieldnotes were written during and immediately after each scheduled observation to reconstruct the observed experiences as accurately as possible.

\subsubsection{Data analysis}

Following suggestions of Creswell \& Clark (2007), Hammersley et at. (2003) and Kvale (1996) the data was compiled, reviewed, and grouped into naturally occurring categories for analysis. The categories that emerged included: school enrollment, retention, teaching strategies and challenges. We further analyzed the information in each of these categories to tease out the most important information in each category. We then compared and contrasted the most important information in each category to the most important information in every other category. These analyses revealed patterns: assessment, enrollment, class placement, strategies and challenges.

Several methods were used to ensure trustworthiness of the study. First, multiple methods (interviews, classroom observations and documentary analysis) were used to ensure triangulation of the findings (Hammersley et at. 2003; Kvale, 1996). Secondly, we spent a prolonged time in the setting, studying and interacting with participants to ensure that they [participants] understood the issues that were being studied. Finally, a constant comparative method of data analysis involving previous research findings used to ensure credibility of our findings.

\section{Findings and Discussion}

\subsection{Inclusion of SGSC in regular schools}

Our inclusive education model (figure 1.) posits that an important step for winning SGSC's trust and confidence for inclusion is to conduct a comprehensive assessment to gain knowledge and understanding of their situation (Ekerberg \&Holmber, 2002; ICCB, 1995). Accordingly, the study revealed that the process of inclusion of SGSC in regular schools was initiated by engaging in street mapping exercises in Accra to identify the locations of SGSC, their activities and sleeping places. The exercise revealed that majority of street children were concentrated around lorry stations, traffic lights, popular restaurants, entertainment places and busy business centers in Accra. Furthermore, the exercise found that lots of young street mothers between the ages of 14 and 21 had children (SGSC). The SGSC were mainly engaged in running errands, begging, washing plates for food vendors, garbage collection, guiding adults with disabilities and babysitting for younger siblings. At night, they ended up in slums around the central business district, Malam Atta, Konkomba market, Agbogbolshie in uncompleted buildings, makeshifts, kiosks and in front of stores to spend the night. They were found sleeping in groups and based on ethnicity for support and protection against rape and thieves.

$<$ Figure 1 about here $>$

This finding is consistent with research conducted in Ghana (CAS, 2003; 2006; 2009) and in other developing countries (Brink, 2001; Ennew, 2003; Gurung, 2004; ICCB, 1995). The activities of SGSC and places of accommodation are inappropriate and unsafe even for adults. They were found sleeping in filthy marshy stretch of land with polluted drains. Many of the young street mothers and SGSC were sleeping in "the open", kiosks and crumbed wooden structures. The young street mothers sleeping at these places become vulnerable for rape or coercion into sexual exploitation. The children born in these circumstances will be forced to spend most part of their early lives on the street because the mothers are often afraid to go back to their families (CAS, 2006; Kuyini et al, 2009). 
Journeying through the street mapping exercise, the inclusion team got deep understanding of street life and the sort of children they were to deal with in schools. In dialoguing about their experiences on the street mapping exercise this conversation developed:

Sara: $\quad$ what do you think about the exercise?

Yebowa: $\quad$ I have learned a lot from it. I cannot get this type of lessons in class

Sara: In what way can that help you when the children are included in your school?

Yebowa: $\quad$ This experience will help me to understand the children and handle them better.

At this juncture, it is important to acknowledge that this finding is not new in street children research (Brink, 2001; Ennew, 2003; CAS, 2003; 2006; 2009; deBeritez, 2001; Street Action, 2010; SAP, 2011). What is new about it, is the phenomenological experiences and the comprehensive knowledge the teachers gained by participating in the inclusion processes of SGSC. This experience is imperative when developing educational program for street children (Brink, 2001; UNESCO, 2009).

\subsection{Identification of SGSC and assessment}

Our inclusive education model (figure.1) again suggests that any quality assessment and identification of street children and their needs for educational purpose, must engage significant stakeholders in the process. The study found that SGSC were identified by social workers in consultation with street community leaders (ethnic group leaders, gang leaders and station leaders). Because of the fluid nature of street children, priority was given to children who had "somewhat permanent" locations to avoid drop-out and absenteeism when enrolled in school. The identification was followed by social investigations. This was conducted by social workers to obtain background information of SGSC and to confirm the data gathered through observation and casual interactions with people in the street communities. Furthermore, it was found that all SGSC in the study lived on the street with their biological mothers or aunties (14-21years). Out of 27 SGSC selected, only $15 \%$ were on the street with both parents. The remaining SGSC $(85 \%)$ were there with either their mothers or aunties (guardians). Finally, we found that majority of SGSC had no idea of their biological fathers because of early separation and disownment of pregnancy.

On the part of needs assessment, we found that SGSC were not in school for several reasons including: (a) Lack of permanent locations, (b) lack of money to pay for school related cost (school uniforms, text books), (c) SGSC were working, (d) Health reasons and (e) lack of awareness.

On the whole, this finding is not dissimilar to research conducted in other countries (Brink, 2001, CAS, 2003; 2006; 2009; deBeritez, 2001; Ennew, 2003; GNCRC, 2005; Hemenway, 1996; ICCB, 1995; SAP, 2011; Street Action, 2010), except that SGSC in Ghana are still closely attached to their mothers and guardians who still exert some authority on them (Kuyini et al., 2009; CAS, 2003; 2006; 2009). The inclusion team positively utilized the existing close relationship among SGSC, mothers and guardians for effective collaboration with mothers and guardians to ensure regular school attendance and retention since collaboration is considered as an important ingredient of inclusion. Ekerberg \& Holmberg (2002), King-Sears (1997) Mastropieri \& Scruggs, (2000), Salend, (2001) and Wilson, (1999) stressed that school parents' collaboration is imperative for any successful inclusion of children in school. They contend that it yields great benefits to teachers and learners as teachers learn greatly about their students and can use the information to support their included students to thrive in school.

\subsection{Class placement}

Street children's class placement can be a dilemma for their inclusion. Alhassan (2009) and CAS (2010) noted that teachers found it hard to place included street and displaced children at appropriate grade-levels due to their ages, educational background and behavior. They contend most street and displaced children are being stigmatized in regular schools while others received unkind treatment from peers (Alhassan, 2009; CAS, 2010). Often, street and displaced children are too old to be placed in the lower class and have insufficient skills to cope with lessons at higher class levels (Alhassan, 2009; CAS, 2010). In this study, we found that all SGSC were placed in Primary (P) 2-4 in seven different schools. 11(9-10 year olds) were placed in primary (P) 2, 10 (10-11year olds) in P3 and 6 (11-12 years olds) in P4 respectively. Furthermore, all SGSC were assessed in mathematics, reading skills and language skills (English and mother tongue). In our conversation with teachers, it unearthed that classes were not assigned to SGSC based only on their performance during the assessment, but also their ages and experiences were taken into account. In the following script, teachers explained how SGSC were assessed:

When SGSC were assessed it was clear to us that some of them were matured more than their ages. They could express themselves very maturely in their native languages. But some of them could not understand us when we 
questioned them in English. But when we explained to them in their native languages they understood things easily. So, we considered maturity and their ages and many other things during the assessment. We also thought of the need not to put other children in danger due to the violent behaviors some SGSC have experienced on the street (primary 4 teacher).

The finding suggests that placement of SGSC in classes marked the beginning of their transition from street to school. Although street and displaced children often complain of being placed at lower levels than their ages and ability levels (Alhassan, 2009; SAP, 2011), it is imperative to assess all their academic and social skills, and behavioral patterns to ascertain the appropriate level at which they can benefit from instruction and succeed in school. Mastropieri \& Scruggs (2000) recommend that it is imperative for assessment to include contextual, skills, performance and curricular domain. Also, Salend (2001) indicates that class placement is the beginnings of transitions. This stage is difficult since it involves learning new things, adjusting to new environment, teaching styles, behavioral expectations and socialization. Therefore, it was imperative that teachers considered SGSC's ages, experiences on the street and maturity for class placement. It is possible that some SGSC are gifted and their needs may not be met if assessment does not include their real life experiences. As argued by (SAP, 2011) that holistic assessments of street children reveal gifted among them.

\subsection{Strategies: retention and attendance}

Knowing the background and the problems facing SGSC, the project team decided to meet some of the basic needs to encourage them to remain in school. Research on streetism noted that the real need of street children is difficult to predict, because they are able to fend for themselves through doing all sort of odd jobs including stealing and prostitution (Brink, 2001; ICCB; 1995; SAP, 2011; CAS, 2003; 2006; 2009). However, what motivated SGSC to remain in school included the provision of: daily food through government school feeding programme; school needs (uniforms, shoes and payment of school related levies) at the start of each academic term; pedagogical materials (text books, pens and pencils); and feeding allowances at home (street). In addition, teachers reported having made school and classroom environment welcoming and interesting to SGSC by showing interest, concern, sympathy, empathy, care and love for SGSC's presence in their schools. Finally, it was also discovered that school-parent collaboration also stimulated school retention and attendance. The school teachers collaborated with social workers who were in direct contact with the street mothers. The social workers visited teachers and SGSC at school on one hand and street mothers on the street on the other hand to discuss issues of attendance, progress and general well being of SGSC. Our interactions with SGSC indicate that more than $65 \%$ of SGSC felt conformable at school because of food, teachers and items received at school. Others were motivated by the security enjoyed and friendship established at school. Our study discovered that out of 27 SGSC enrolled in schools, only 5 dropped out throughout the 3-year period. More details about SGSC's retention and attendance were echoed in our dialogue with a class four teachers:

Ofori: How do you manage to keep SGSC in school?

Aduna: Well, it is not easy. A lot of things have happened. We are working very hard with NGOs and Social Workers to keep them here. The first time they were admitted they weren't comfortable staying with us. There were a lot of absenteeism, they could skip school for two to three days, and sometimes they wouldn't come the whole week. But for the past three terms it has improved greatly.

Ofori: So, what actually do you do to motivate them to come?

Aduna: You have to understand these children, respect them and acknowledge the fact that they have their own culture. We also build personal relationships with them and they know that we care very much about them. They want to be sure that you are concerned and interested in what they do. So this is exactly what we do for them. When they don't come to school, we contact the social worker to find out why. When they are not feeling fine we inform social workers and ask them to go home. Besides, the things they get from the NGO are motivating factors because they will not get them if they don't come to school.

Ofori: What about class attendance?

Aduna: They come alright, and they are motivated to learn. Most of what we do with them reflect their real life experiences such as using money to learn mathematic, storytelling and parties at the end of each term. We also give them responsibilities like class prefect $\mathrm{s}$ /he has to bring register and return it everyday. All these things stimulate their interest in school and creating a very lovely classroom environment by giving them chance to tell stories even if they cannot do it in English, we allow them to use vernacular. I think all these make them happy to be here [school].

Apart from this, mothers of SGSC were also trained in income generating activities - pedicure and manicure to generate income to support themselves and their children. Also, our finding suggests that inclusion of SGSC can be expensive for 
societies or countries where social problems are not highly prioritized because social workers and regular teachers were paid extra allowances for the additional responsibility they shouldered. This account also disagrees with Brink (2001), who contends that any placement of street children in formal rehabilitation institutions contributes to only to their isolation. In a nutshell, it can be gleaned from the finding that inclusion of street children in formal institution is possible only when all necessary structures for inclusion are put in place. For example, King-Sears (1997), Mastropieri \& Scruggs (2000), Salend (2001) and Wilson (1999) suggest that successful inclusion programs must identify parents and student preferences; promote sense of empowerment for regular teachers; provide opportunities and supports for friendship development; and design programs to meet the needs of all children in classrooms. These, they argued, are the basic structures that need to be in place for children to thrive in school.

\subsection{Enhancing learning outcomes}

SGSC's first and second year school and monitoring reports were examined to evaluate their progress in school. We also interviewed and observed teaching sessions to find out strategies used to enhance learning outcomes of SGSC. The study revealed that teachers used varied strategies to improve academic and social wellbeing of SGSC. With the academic skills, it was found that teachers used explicit instruction, cooperative learning and differentiated learning strategies while SGSC's social skills were enhanced by using group play, folk tales and storytelling during lessons and games.

\subsubsection{Academic skill}

To examine the impact of SGSC's progress, school reports for first term of academic year 2007/2008 were analyzed. It revealed that only 6 out of 27 SGSC scored above average mark (50\%) in 4 subjects, the remaining 21 SGSC scored less than $40 \%$ in all the subjects. The second term reports of the academic year 2008/2009 indicated that 11 out of 27 scored more than $50 \%$ in $4-6$ subjects, whereas 16 passed below 50\% in 4-6 subjects. In the third term of the academic year $2008 / 2009$, there was a significant increase in performance. Out of 25 SGSC (2 dropped out), more than half (21) scored above $50 \%$. Only 4 SGSC could not make it to the next class. In the first term of academic year 2009/2010, performance decreased significantly. Only 10 out of 24 SGSC (1 dropped out) made a pass mark (50\%), the remaining 14 scored below average. In the second and third terms of the academic year 2009/2010, there were significant academic gains as only 3 SGSC could not score above 50\% in 4 subjects. The remaining 21 SGSC scored above $50 \%$ in $4-6$ subjects. In our interviews with teachers concerning teaching strategies, we asked:

Amina: Tell us how you are able to teach SGSC to improve academically?

Daniel: It depends on pupil to pupil. It is Ok to teach all SGSC in a lesson without modifying the content. But for some, we definitely have to use direct instructions. For instance, Amamah had no formal school experience but she was admitted to class 2 because of her age and determination to learn. We worked out a plan that Amamah will always sit closer to my desk and work on different concepts and contents while participating in the general classroom activities like storytelling and singing. Amamah was also paired with some two selected pupils to do basic activities like reading, matching, naming and simple additions. This plan helped her very much. In other cases, this strategy does not work. We had to combine different strategies like cooperative learning techniques and pairing. For example, some SGSC are not able to work together with peers because they end up fighting. Such SGSC needed different techniques like behavior management techniques. In such cases, we seek support from special educators and social workers.

Susan: Are there other strategies that work with SGSC in your class?

Lizy: Initially, some SGSC were reluctant to attend lessons. Even when they attended, they were only interested in drawing and playing games. When we realised that they were more at ease, we introduced them to basic literacy with pictures and materials. Real objects like counters, money (photocopies) were used to teach concept of quantity and numbers. At first, SGSC who had school experience tried to hide behind the statement that the activities we were using were far below their levels. But at the end of it all they realised they were able to learn something. Even though progress is slow, they become very proud of their success.

The study also discovers that different teaching strategies are required for instruction of SGSC. Whereas some SGSC required behavior management skills to be able to progress in regular school, others needed differentiated teaching techniques. Although explicit instruction was not applicable to all SGSC, it was useful for some SGSC. Ekerberg \& Holmberg (2002), King-Sears (1997), Mastropieri \& Scruggs (2000), Salend (2001) and Wilson (1999) contend that most students with special needs will be better served in regular schools by using cooperative learning techniques, one-on-one teaching, peer -tutoring and differentiated instructions. Brink (2001) also found reciprocal teaching to be useful for street children. However, King-Sears (1997) disagreed when it comes to explicit instruction. He argued that 
students with special needs will not thrive in inclusive setting without explicit instructions because it enables both students with and without special needs to learn content. This view was echoed when teachers emphatically stated that some SGSC understood better only when they used explicit instruction.

Teacher variables such as experience, training and attitudes could also be factors that led to successful learning outcomes for SGSC. Thousand, Rosenberg, Bishop \&Villa (1997) found that teachers with experience in teaching learners with disability were more positive and successful with learners than those without such experiences. Since all the teachers of SGSC in this study had more than 4 years teaching experience with additional training in special needs, it is possible that their experience had profound influence on the positive learning outcomes for SGSC.

\subsubsection{Social skills}

Studies indicate that street children face difficulty to thrive in school because they lack social skills and do not take instructions from teachers (Brink, 2001; CAS, 2006; 2010). However, our study revealed mixed findings when teachers used various social skills instruction strategies to support SGSC on their social behaviors in school. In examination of monitoring reports for the first, second and third terms of academic year 2007/2008-2008/2009, heard teachers' remarks for SGSC included:

excellent academic performance but difficult to accommodate peers; child is very friendly but lacks concentration in class, child likes fighting; child is not neat; child is playful and quick tempered; child is talented in music but comes to school with objects like blade, nails and metals; child's performance is good but not able to relax/stay calm in group work; child is kind and friendly but not able to follow instructions; child teases and bullies peers; child sleeps in class; child cries for little provocations; child is talented but difficult maintaining positive relationship with peers (School B headteacher).

Our investigations on these issues revealed that there had been several brainstorming sessions, training and consultations between special educators, social workers and regular teachers regarding means of improving SGSC's social skills. We found that role-play, storytelling, folk tales, collaborative learning activities, discussions of events watched on TV and direct teacher intervention (direct talks with SGSC, limit setting and teaching of polite ways of saying and doing things) were the main strategies used in schools. For example, teachers revealed that they paired SGSC and peers during lessons such as English, mathematic and science activities and discussions of lessons learned from stories and events to improve acceptance, conversation and interaction skills. According to Brink (2001), King-Sears (1997), ICCB (1995), SAP (2011) and Wilson (1999), pairing strategy is not only meant to acquire academic skills, but also to brings about change in learners' behavioral pattern through working collaboratively with others, cooperation and the spirit of collective efforts. Teachers also staged carefully selected plays and stories in which SGSC and peers were the main participants. Discussions generated from such activities improved all the pupils' social skills and reinforced good cultural and moral values. In our conversation with teachers, one of them said:

SGSC are now getting used to instructions from us and are now learning to trust us. They are taught how to speak to people who are older than them and they learn to be in group and to accommodate others. Through this, they feel better about themselves and there is less need to behave negatively. Their way of life also leads us to create more flexible options that allow them to demonstrate their competencies and goal achievements (Primary 4 teacher).

\subsection{Challenges}

\subsubsection{Specific learning problems}

Teachers indicated that some SGSC had specific learning problems and the problems were demonstrated in many ways. The script below indicates some of the challenges:

SGSC' know the exact values of money and are very smart in money dealings. But when they are to do the same calculations (equivalent of money) on paper, say $7+15$, they get nowhere. But when you ask them orally $7 \mathrm{Gh}$. Cedi $+15 \mathrm{Gh}$. cedis they quickly tell you the answer. Another example is their language skills: many street children are good talkers and can speak many languages. They can convince and even manipulate adults. But when they are to read or write the same words they use in talking, it doesn't connect (Primary 2 teacher).

\subsubsection{Lack of support from home}

Teachers indicated that parents' inability to help SGSC do school work at home was a serious drawback of SGSC's inclusion. Interactions with parents and social workers indicated that parents could not support their children's home 
work due to: (a) illiteracy, (b) inappropriate home environment for learning, (c) lack of time, and (e) psychosocial problems, disabilities and ill-health (due to drug addiction and other health related problems).

\subsection{Behavior problems}

The study has also revealed that adjustment to classroom and school environments, difficulty concentrating on task and disruptive behaviors were challenges faced by teachers in school. The challenges became enormous given the large class sizes and the time needed to concentrate on SGSC who had difficulties to cope with instruction. The following script exemplifies some of the challenges:

Talata is very sociable and copes very well with school work. She is skillful in organizing games (boys-boys games) and events and her peers like her much in school. These games tend to wear her out sometimes. She participates very well in class discussion only when she is in good mood and prefers doing her exercises alone. But Talata has three main problems: a) Most often she has serious concentration problems, b) when angry, she becomes very aggressive and hits everybody in class, and d) she steals items from peers. But she has a very strong interest in schooling and a promising future as she is likely to overcome her current weakness, though progress is very slow.

Teacher indicated using several strategies for pupils like Talata, but certain behaviors like stealing, hitting when angry and concentration were still difficult to change. Other challenges included large class sizes and lack of pedagogical materials.

\section{Conclusion}

The aim was to find out the strategies being developed to include SGSC in Accra. The finding demonstrates that a comprehensive knowledge of SGSC's locations, activities and issues affecting them on the street are key steps to their successful inclusion in regular schools. Inclusion of SGSC requires responsible and willing leadership as well as training on and exposure of teachers and special educators to issues of streetism. Furthermore, inclusion of SGSC will not be effective without strong financial backing from government and non-governmental organizations while effective collaboration with all stakeholders- street children, opinion leaders in the street community- is vital for successful inclusion. Finally, the study demonstrates that explicit instruction; differentiated teaching, and social skills strategies could be good instructional tools for supporting street children in regular schools.

\subsection{Limitations of the study}

Limitations to this study should be noted. The study looked at inclusion of only one category

[SGSC] of street children in regular schools and therefore the finding cannot be generalized. Also, it is worth noting that these children were 'somewhat' under control of their mothers and aunties which stimulated their successful inclusion. Thus, the strategies used presently may not necessarily be applicable to street children (above 14 years) who live independently without any control from adults or parents.

\subsection{Acknowledgment}

The authors would like to express their profound thanks to Ricerca e Cooperazione, Ghana Department of Social Welfare, CAS and SAID for the opportunity given to us to be part of this project. Our gratitude also goes to The Italian Ministry of Foreign Affairs for financing The Street Children's Project. 


\section{References}

Abosi, O. (2007). Educating children with Learning disabilities in Africa. Learning disabilities research \& practice, 22(3), 167-172. http://dx.doi.org/10.1111/j.1540-5826.2007.00242.x

Alhassan, A.R.K. (2009). Unaccompanied minor asylum seekers in Norway: Educational needs and adapted Education. Oslo: Oslo University College.

Anthony, J.H. (2009), Access to Education for Students with Autism in Ghana: Implications for EFA, Report 2010.

Brink, B. (2001). Working with street children: reintegration through education: support for learning vol.16 No. 2.

Catholic Action for Street children. (2010). The history towards the future. Newsletter 51 October 2010.

Catholic Action for Street children. (2006). A report on the current situation in particular areas of Accra City and Ashaiman township.

Catholic Action for Street children. (2003). The Ghanaian street child.

Casely-Hayford, L. (2002).A Situational Analysis of Special Needs Education in Ghana.

Cresswell, J.W \& Plano, C. (2007). Designing and conducting mixed methods research. Thousand Oaks, CA, Sage.

deBeritez, S.T.(2001). What Works in Street Children programming. The JUCONI Mdelm: Maryland 21202 USA. International Youth Foundation.

Ekeberg, R.T., Holmberg, J.B. (2002). Tilpasset Oppléring og spesialpedagogisk arbeid I skolen (2.utg). Oslo: Universitetsforslaget.

Ennew, J. (2003). Difficult Circumstances: Some reflections on "street children" in Africa.

Ghana National Coalition for Right of Children (GNCRC). (2005). The Ghana NGO report to the UN committee on the rights of the child.

Harmmersley, M. \& Atkinson, P. (2003).Ethnography, Principles in practice. London and New York: Routledge Taylor \& Francis Group.

Hemenway, D. (1996), Street children and education: Cross-cultural comparisons and program implications.

International Catholic Child Bureau (ICCB). (1995). Working with street children-selected case studies for Africa, Asia, and Latin America. Paris: UNESCO.

Kuyini, A.B. \& Desai, I. (2007). Providing instruction to students with special needs in inclusive classrooms in Ghana: Issues and challenges. International Journal of Whole Schooling Vol. 4, No. 1.

Kuyini, A.B. Alhassan, A, Tullerud, I.Weld. H. \& Haruna, I. (2009). Traditional kinship foster care in northern Ghana: the experiences and views of children, carers and adults in Tamale. Child \& Family Social Work. 14, 440-449. http://dx.doi.org/10.1111/j.1365-2206.2009.00616.x

Kvale, S. (1996). Inter Views: An introduction to qualitative research interviewing. Thousand Oaks, CA, Sage.

King-Sears, M.E. (1997). Best academic Practices for inclusive classrooms. Focus on Exception Children 29(7):1-21.

Mastropieri M.A. \& Scruggs, T.E. (2000). The inclusive classroom strategies for effective instructions. New Jersey: Merrill, Upper Saddle River.

Obi, F., Mamah, v. \& Avoke, K. (2007).Inclusive education in an emerging country: The state of teacher preparation in Ghana: Journal of International Special Needs Education, 10,31-39.

P.A.U. Education \& UNESCO. (2005).The white book of our future, Egypt. Muntaner, 262, $3^{\circ}$ - 08021 Barcelona (Spain).

Salend, S.J. (2001). Creating inclusive classrooms effective and reflective practices ( $4^{\text {th }} E d$ ). New Jersey: Merrill, Upper Saddle River.

Special Attention Project. (2011). Street Children and Learning Difficulties, Research on the Role of Learning Problems in Children in the Streets.

Street Action. (2010). Including street children: A Situation analysis of street children in Durban, South Africa.

Thousand, J., Rosenberg, R.L., Bishop, K. D. Villa, R.A. (1997). The evolution of secondary inclusion. Remedial and Special Education; Austin. 18, (5), 170-189.

UNESCO. (2009). Policy Guidelines on Inclusion in Education: France. UNESCO ED-2009/WS/31 
UNESCO. (1994). The Salamanca Statement and Framework For Action on Special Needs Education World Conference on Special Need Education: Access and Quality. UNESCO ED-94/WS/18.

Wilson, B.A. (1999). Inclusion empirical guidelines and unanswered question. Education and Training in Mental Retardation and Developmental Disabilities 34(2): 119-33.

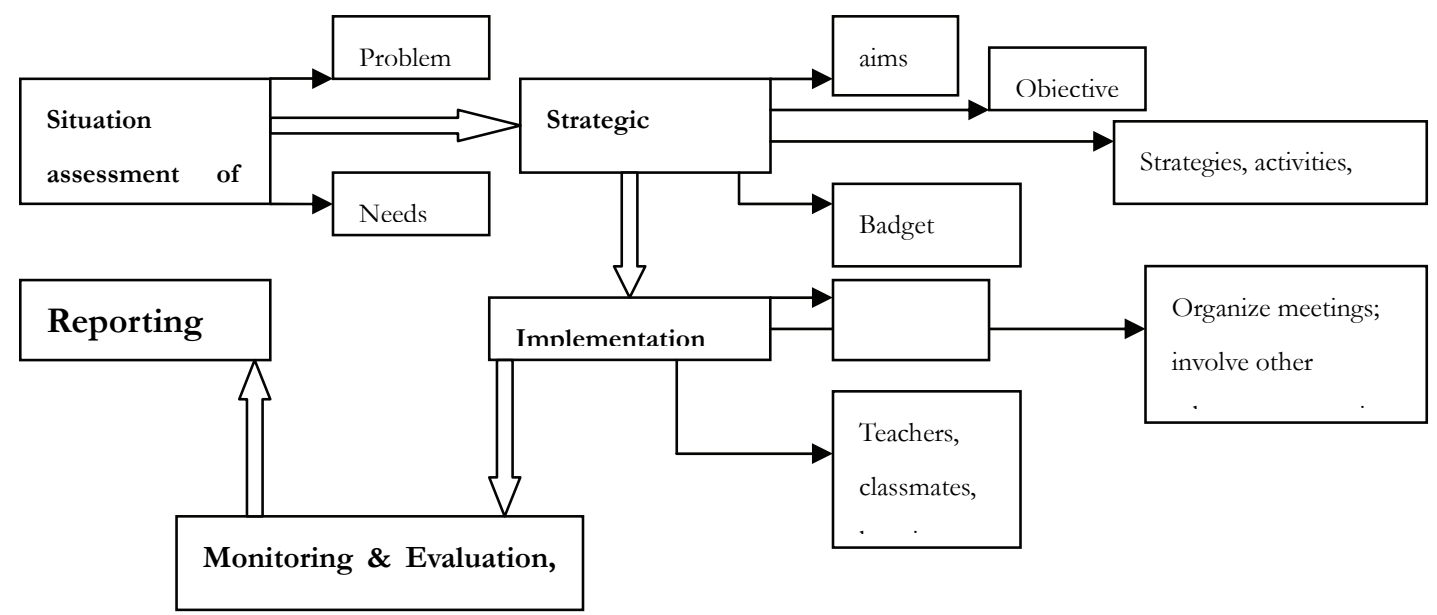

Figure 1. Inclusion model for street children

(This framework explains the five series of actions that need to be taken in order to include street children in regular school. The key actions include: situation assessment of SGSC's situation, strategic planning, implementation, continuous monitoring and assessment, and reporting of success and challenges. Please see page 4 , heading 2 of this article for detail explanation.) 